\title{
Association of Cognitive Impairment with Serum Lipid/Lipoprotein among Chinese Nonagenarians and Centenarians
}

\author{
Chang-Quan Huang Bi-Rong Dong Hong-Mei Wu Yan-Ling Zhang \\ Jin-Hui Wu Zhen-Chan Lu Joseph H. Flaherty \\ Department of Geriatrics, West China Hospital, Sichuan University, Chengdu, China
}

\section{Key Words}

Lipid/lipoprotein · Cognitive impairment • Nonagenarians

and centenarians $\cdot$ Chinese population tein. In summary, we found that levels of serum lipid/lipoprotein were not directly correlated with cognitive impairment among Chinese nonagenarians and centenarians.

Copyright $\odot 2009$ S. Karger AG, Basel

\section{Introduction}

About $10 \%$ of people older than 65 years have cognitive impairment, ranging from mild deficits to dementia [1]. Abnormality of serum lipid/lipoprotein has been viewed as a common and potentially modifiable risk factor for cognitive disorders $[2,3]$. More than 10 prospective and cross-sectional observational studies have demonstrated the association of cognitive impairment with abnormal levels of serum lipid/lipoprotein [including total cholesterol (TC), triglycerides (TG), low-density lipoprotein (LDL) cholesterol and high-density lipoprotein (HDL) cholesterol] [2-15]. Common to most of these studies, however, was the relatively young age of the participants. There were only two studies in which subjects were all aged 85 years or above, and the results of them both showed that cognitive impairment was only associated with the levels of HDL and was independent of the levels of TC, TG, and LDL $[16,17]$. This showed that the association of cognitive impairment with abnormal levels of serum lipid/lipoprotein in younger adults was different

\section{KARGER \\ Fax +4161306 1234 E-Mail karger@karger.ch} www.karger.com

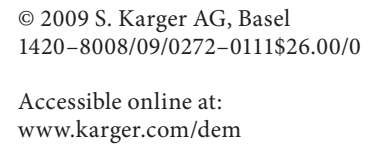

Prof. Bi-Rong Dong

Department of Geriatrics, West China Hospital

Sichuan University, GuoXueXiang 37

Chengdu, 610041 (China)

Tel. +861343805 0931, E-Mail sanyuan319@yahoo.com.cn 
from that in the oldest old population. The two studies took place in the United States and The Netherlands [15, 16]. As the population of older persons increases, the number of cognitively impaired older individuals can be expected to rise [17, 18]. However, only few studies have explored the association of cognitive impairment with abnormal levels of serum lipid/lipoprotein in an oldest old population and there still have been no relevant data of a Chinese oldest old population. In the present study, we observed the association of cognitive impairment with abnormal levels of serum lipid/lipoprotein among very old people using a Chinese cohort aged $90-108$ years.

\section{Subjects and Methods}

\section{Study Subjects}

The present study is part of the Project of Longevity and Aging in Dujiangyan (PLAD). The PLAD was performed in Dujiangyan $(2,311,709$ inhabitants, 870 aged 90 years or more; men: $32.6 \%$, women: $67.4 \%$; located outside the urban area of Chengdu). In April 2005, 870 persons aged 90 years or more were collected from the population. The study protocol was approved by the Research Ethics Committee of the Sichuan University. Informed consent was obtained from all participants (as well as their legal proxies). Trained personnel visited all study participants at their homes for data collection, biological specimen collection, and anthropometric measurements. Sociodemographic characteristics and lifestyle habits were collected by using a general questionnaire. We excluded the subjects who suffered from post-stroke pain, Alzheimer's disease or Parkinson's disease, did not complete the Mini-Mental State Examination (MMSE) test, or reported the use of drugs affecting the serum lipid/lipoprotein levels. Overall, 21 men and 26 women were not eligible for the study because they had already died or moved away from the area. Of 262 men and 561 women who were interviewed, 23 men and 31 women suffered from poststroke pain, Alzheimer's disease or Parkinson's disease, 5 men and 41 women did not complete the MMSE test, 8 men and 13 women reported the use of drugs affecting the serum lipid/lipoprotein levels, such as antilipemic agents which had been shown to decrease serum lipoprotein levels in humans, and 2 men and 5 women both did not complete the MMSE test and reported the use of drugs affecting the serum lipid/lipoprotein levels. Finally, we included 709 participants (228 men, 481 women) in the analysis.

\section{Assessment of Cognitive Function}

Cognitive function was measured with the 30-item MMSE, which is a global test with components of orientation, attention, calculation, language and recall. Cognitive impairment was defined as a score below 24 on the MMSE [19]. This score has shown a sensitivity of $80-90 \%$ and a specificity of $80-100 \%$ for a diagnosis of dementia $[19,20]$. To decrease methodological bias and assure methodological reliability, the administrator (1) reviewed the MMSE procedure and grading system outlined in a short booklet and video, (2) observed a geriatrician conduct the MMSE on residents not part of the study and (3) was supervised when conducting the MMSE on residents not part of the study. The MMSE was administered to the subjects that gave consent for study participation. Subjects were categorized as follows: cognitive impairment (scores between 0 and 18), mild cognitive impairment (scores between 19 and 24) and normal (scores between 25 and 30).

\section{Measurement of Serum Lipid/Lipoprotein}

Blood samples were collected after an overnight fast (at least $8 \mathrm{~h}$ ) for measurement of serum lipid/lipoprotein. Lipid/lipoprotein levels including serum TC, TG, HDL and LDL were determined by standard laboratory techniques (performed by a technician in the biochemistry laboratory of Sichuan University). Abnormal levels of serum lipid/lipoprotein were defined according to the criteria provided by the Chinese Medical Association 2004. Normal criteria were: TC $<5.18 \mathrm{mmol} / \mathrm{l}, \mathrm{TG}<1.7 \mathrm{mmol} / \mathrm{l}, \mathrm{LDL}$ $<3.37 \mathrm{mmol} / \mathrm{l}$ and HDL $>1.04 \mathrm{mmol} / \mathrm{l}$.

\section{Assessment of Covariates}

The baseline examination included information on age (years), educational levels (illiteracy, primary school, secondary school, college and postgraduate), smoking habits (yes or no), alcohol consumption (yes or no), tea consumption (yes or no), exercise (yes or no), serum uric acid ( $\mu \mathrm{mol} / \mathrm{l})$, systolic blood pressure $(\mathrm{mm}$ $\mathrm{Hg}$ ), diastolic blood pressure ( $\mathrm{mm} \mathrm{Hg}$ ), sleep time during 1 day, satisfaction of sleep, and body mass index (BMI). The BMI was calculated as body weight in kilograms divided by height in meters squared. Right arm blood pressure (sitting or recumbent position) was measured twice to the nearest $2 \mathrm{~mm} \mathrm{Hg}$ using a standard mercury sphygmomanometer (Korotkoff phases I and V) by trained nurses or physicians. The mean value of two measurements was used to calculate the systolic and diastolic blood pressure. Fasting plasma glucose (FPG) and serum uric acid were determined by standard laboratory techniques (performed by a technician in the biochemistry laboratory of Sichuan University). The other covariates were collected by using a general questionnaire. Information on sleep quality was obtained from another questionnaire where 1-4 meant very satisfactory, generally satisfactory, generally unsatisfactory and very unsatisfactory, respectively; the higher scores indicated worse sleep quality.

\section{Statistical Analysis}

All of the statistical analyses for this study were performed with the SPSS for Windows software package, version 11.5 (SPSS Inc., Chicago, Ill., USA). Baseline characteristics were compared between those with and those without prevalent cognitive impairment using the $\chi^{2}$ or Fisher's exact test (where the expected cell count was $<5$ ) for categorical variables and unpaired Student's $t$ test for continuous variables. The association between MMSE scores and serum lipid/lipoprotein levels or some covariates was assessed using Pearson correlation analysis. Cognitive impairment was compared between those with and those without abnormal levels of serum lipid/lipoprotein using the $\chi^{2}$ or Fisher's exact test (where the expected cell count was $<5$ ). Multiple logistic regression was used to estimate the odds ratio (OR) and 95\% confidence interval (CI) of abnormal levels of serum lipid/lipoprotein as a function of increased cognitive impairment. To assess the association between abnormal levels of serum lipid/lipoprotein and cognitive impairment which demographic and clinical factors do not explain, multivariate-adjusted ORs were calculated for each cognitive impairment index; $p<0.05$ was considered to be statistically significant, and all $\mathrm{p}$ values were two-sided. 
Table 1. Baseline characteristics according to cognitive function $(\mathrm{n}=709)$

\begin{tabular}{|c|c|c|c|c|c|c|c|c|}
\hline & \multicolumn{2}{|c|}{ Cognitive impairment } & \multicolumn{2}{|c|}{ Normal cognitive function } & \multicolumn{2}{|c|}{$\chi^{2}$ or mean difference } & \multicolumn{2}{|l|}{$\mathrm{p}$ value } \\
\hline & $\begin{array}{l}\text { men } \\
(n=87)\end{array}$ & $\begin{array}{l}\text { women } \\
(\mathrm{n}=322)\end{array}$ & $\begin{array}{l}\text { men } \\
(\mathrm{n}=141)\end{array}$ & $\begin{array}{l}\text { women } \\
(\mathrm{n}=159)\end{array}$ & men & women & men & women \\
\hline Age, years & $93.54 \pm 3.27$ & $94.17 \pm 3.56$ & $92.87 \pm 2.78$ & $93.22 \pm 3.20$ & 0.67 & 0.95 & 0.451 & 0.174 \\
\hline MMSE score & $11.00 \pm 4.27$ & $10.79 \pm 4.13$ & $21.33 \pm 2.99^{* *}$ & $19.45 \pm 2.26^{* *}$ & -10.33 & -8.66 & $<0.001$ & $<0.001$ \\
\hline Triglycerides, mmol/l & $1.19 \pm 0.59$ & $1.23 \pm 0.65$ & $1.25 \pm 0.54$ & $1.28 \pm 0.87$ & -0.06 & -0.05 & 0.884 & 0.895 \\
\hline Total cholesterol, mmol/l & $4.09 \pm 0.82$ & $4.18 \pm 0.80$ & $4.10 \pm 0.86$ & $4.17 \pm 0.92$ & -0.01 & 0.01 & 0.753 & 0.767 \\
\hline $\mathrm{HDL}, \mathrm{mmol} / \mathrm{l}$ & $1.51 \pm 0.34$ & $1.57 \pm 0.60$ & $1.65 \pm 0.841$ & $1.62 \pm 0.99$ & -0.14 & -0.05 & 0.421 & 0.384 \\
\hline $\mathrm{LDL}, \mathrm{mmol} / \mathrm{l}$ & $2.23 \pm 0.60$ & $2.25 \pm 0.59$ & $2.21 \pm 0.55$ & $2.32 \pm 0.66$ & 0.02 & -0.07 & 0.863 & 0.754 \\
\hline $\mathrm{FPG}, \mathrm{mmol} / \mathrm{l}$ & $4.59 \pm 1.39$ & $4.41 \pm 1.45$ & $4.45 \pm 1.41$ & $4.65 \pm 1.76$ & 0.14 & 0.24 & 0.449 & 0.376 \\
\hline Serum uric acid, $\mu \mathrm{mol} / \mathrm{l}$ & $331.7 \pm 84.89$ & $312.53 \pm 86.09$ & $325.15 \pm 91.09$ & $316.39 \pm 86.29$ & 6.55 & -3.86 & 0.739 & 0.814 \\
\hline Systolic BP, mm Hg & $142.36 \pm 20.83$ & $139.34 \pm 22.49$ & $139.98 \pm 23.49$ & $141.35 \pm 24.30$ & 0.38 & -2.01 & 0.947 & 0.636 \\
\hline Diastolic BP, mm Hg & $73.66 \pm 12.08$ & $72.74 \pm 12.14$ & $72.74 \pm 12.02$ & $72.68 \pm 11.72$ & 0.92 & 0.06 & 0.924 & 0.997 \\
\hline Sleep time during 1 day, $\mathrm{h}$ & $11.18 \pm 2.39$ & $11.32 \pm 2.13$ & $11.13 \pm 2.15$ & $11.50 \pm 7.27$ & 0.05 & 0.18 & 0.866 & 0.795 \\
\hline Satisfaction of sleep & $1.55 \pm 0.84$ & $1.74 \pm 0.86$ & $1.52 \pm 0.78$ & $1.62 \pm 0.97$ & 0.03 & 0.12 & 0.875 & 0.765 \\
\hline \multicolumn{9}{|l|}{ Smoking habits } \\
\hline Former & $78 / 87(89.6)$ & $157 / 313(50.1)$ & $110 / 137(80.2)^{*}$ & $79 / 157(50.3)$ & 3.49 & 0.09 & 0.043 & 0.762 \\
\hline Current & $69 / 87(79.3)$ & $103 / 320(32.1)$ & $93 / 141(65.9)^{*}$ & $49 / 159(31.8)$ & 4.67 & 0.51 & 0.031 & 0.775 \\
\hline \multicolumn{9}{|l|}{ Alcohol consumption } \\
\hline Former & $63 / 86(73.3)$ & $96 / 318(30.2)$ & $85 / 139(61.1)^{*}$ & $41 / 155(26.5)$ & 3.46 & 0.71 & 0.042 & 0.400 \\
\hline Current & $36 / 86(41.9)$ & $72 / 319(20.1)$ & $53 / 141(37.5)$ & $32 / 159(20.1)$ & 0.41 & 0.29 & 0.522 & 0.593 \\
\hline \multicolumn{9}{|l|}{ Tea consumption } \\
\hline Former & $62 / 86(72.1)$ & $90 / 316(28.5)$ & $109 / 136(80.1)$ & $48 / 156(30.7)$ & 1.32 & 0.85 & 0.251 & 0.356 \\
\hline Current & $58 / 87(66.7)$ & $86 / 321(26.8)$ & $104 / 151(68.8)$ & $49 / 159(31.8)$ & 1.93 & 0.26 & 0.165 & 0.607 \\
\hline \multicolumn{9}{|l|}{ Exercise habits } \\
\hline Former & $31 / 86(36.1)$ & $96 / 313(31.7)$ & $50 / 137(36.5)$ & $48 / 155(31.0)$ & 2.38 & $<0.01$ & 0.123 & 0.979 \\
\hline Current & $31 / 87(35.6)$ & $124 / 317(39.1)$ & $64 / 139(46.0)$ & $62 / 158(39.2)$ & 0.01 & $<0.01$ & 0.969 & 0.948 \\
\hline \multicolumn{9}{|l|}{ Educational levels } \\
\hline Illiteracy & $50 / 87$ & $249 / 322$ & $34 / 139$ & $123 / 159$ & & & & \\
\hline Primary school & $26 / 87$ & $55 / 180$ & $70 / 139$ & $18 / 159$ & & & & \\
\hline \multirow[t]{2}{*}{ Secondary school } & $9 / 87$ & $17 / 180$ & $25 / 139$ & $12 / 99$ & & & & \\
\hline & $2 / 87$ & $1 / 180$ & & 6/99 & & & & \\
\hline College and postgraduate & & & $10 / 139$ & & 26.16 & 19.57 & $<0.001$ & 0.001 \\
\hline
\end{tabular}

Baseline characteristics were compared between those with and those without prevalent cognitive impairment.

${ }^{*} \mathrm{p}<0.05$; ${ }^{* *} \mathrm{p}<0.01$ vs. cognitive impairment group using the $\chi^{2}$ or Fisher's exact test (where the expected cell count was $<5$ ) for categorical variables and unpaired Student's t test for continuous variables. A p value $<0.05$ was considered to be statistically significant.

$\mathrm{BP}=$ Blood pressure. Figures in parentheses indicate percentages.

\section{Results}

\section{Baseline Characteristics and Prevalence of Cognitive}

Impairment and Abnormal Serum Lipid/Lipoprotein

Among the 709 volunteers, mean age was $93.6 \pm 3.4$ years (range 90-108 years) and 481 (67.8\%) were women, including 81 centenarians. Ninety percent of subjects lived in the countryside. The mean cognitive function score for the old population was 14.9 (SD 6.0, range 3-26). Men had significantly higher cognitive function scores than women $(17.4 \pm 6.1$ vs. $13.6 \pm 5.4, \mathrm{p}<0.05)$. Only 41 volunteers had scores higher than 24 (34 male, 7 female), so we defined subjects with an MMSE score lower than
18 as having a cognitive impairment. In the oldest old population, the total prevalence rate of cognitive impairment was $57.8 \%$, the prevalence rate among males was $38.0 \%$ and among females it was $67.2 \%(\mathrm{p}<0.001)$. The total prevalence rate of abnormally elevated serum TG was $13.7 \%$, the prevalence rate among males was $15.3 \%$ and among females it was $12.9 \%(\mathrm{p}>0.05)$. The total prevalence rate of abnormally elevated serum TC was $10.6 \%$, the prevalence rate among males was $11.4 \%$ and among females it was $10.3 \%$ ( $p>0.05)$. The total prevalence rate of abnormally elevated serum LDL was $5.1 \%$, the prevalence rate among males was 3.5\% and among females it was $5.8 \%(\mathrm{p}>0.05)$. The total prevalence rate 
Table 2. Pearson correlation analysis for cognitive function

\begin{tabular}{lccccc}
\hline Variable & \multicolumn{2}{c}{ Men $(\mathrm{n}=228)$} & & \multicolumn{2}{c}{ Women $(\mathrm{n}=481)$} \\
\cline { 2 - 3 } \cline { 6 - 7 } & coefficient & $\mathrm{p}$ value & & coefficient & $\mathrm{p}$ value \\
\hline Age & -0.21 & $<0.01^{* *}$ & & -0.13 & $<0.01^{* *}$ \\
FPG & -0.05 & 0.49 & & 0.07 & 0.11 \\
Triglycerides & 0.03 & 0.66 & & 0.04 & 0.43 \\
Total cholesterol & 0.02 & 0.81 & & 0.00 & 0.99 \\
HDL & 0.12 & 0.07 & & 0.03 & 0.48 \\
LDL & -0.03 & 0.65 & & 0.04 & 0.38 \\
\hline
\end{tabular}

${ }^{* *} \mathrm{p}<0.01$ vs. cognitive impairment group.

of abnormally elevated serum HDL was $5.7 \%$, the prevalence rate among males was $5.7 \%$ and among females it was $5.7 \%(p>0.05)$. There were no different levels of TC, TG, LDL and HDL between subjects with and without cognitive impairment; subjects with cognitive impairment were significantly more likely to report smoking habits (former or current) and alcohol consumption (former, but not current) than men without cognitive impairment (however, this was not observed in women without cognitive impairment; table 1).

Correlations between Cognitive Function and Clinical Variables (Including Serum Lipid/Lipoprotein)

Correlations between cognitive function and clinical variables (including serum lipid/lipoprotein) are shown in table 2. Scores on the MMSE did not significantly correlate with TC, TG, LDL, HDL and FPG in both genders. Highly significant correlations (with coefficient $r=-0.1$ and -0.2 , in women and men, respectively; $\mathrm{p}<0.01$ ) were found in both genders between scores on the MMSE and age.

\section{Levels of Serum Lipid/Lipoprotein and Risk for \\ Cognitive Impairment}

We assessed whether abnormal levels of serum lipid/ lipoprotein were associated with an increased risk for cognitive impairment (table 3). After adjustment for age, BMI, smoking habits, alcohol and tea consumption, exercise, FPG, systolic blood pressure, diastolic blood pressure, sleep time during 1 day, sleep quality, comparing abnormal with normal levels of serum lipid/lipoprotein, the ORs of cognitive impairment were 1.03 (95\% CI, $0.39-2.75$ ) in men and 1.52 (95\% CI, 0.79-2.90) in women, 0.99 (95\% CI, 0.43-2.29) in men and 1.12 (95\% CI, $0.62-2.05)$ in women, 0.24 (95\% CI, 0.04-1.36) in men and 1.97 (95\% CI, 0.85-5.00) in women, 1.55 (95\% CI, $0.42-5.36)$ in men and 1.28 (95\% CI, 0.55-2.99) in women according to TC, TG, LDL and HDL levels, respectively. This indicates that ORs of cognitive function to abnormal levels of serum lipid/lipoprotein were all insignificant.

\section{Discussion}

In cross-sectional observations in community-dwelling Chinese nonagenarians and centenarians, there was a high prevalence of cognitive impairment (above 50\%) and a very low average score of cognitive function (lower than 18 on the MMSE); compared with men, women had a higher prevalence of cognitive impairment and a lower mean cognitive score. Based on cross-sectional observations in community-dwelling oldest old persons, we found no causal association between risk for cognitive impairment and levels of serum lipid/lipoprotein in Chinese nonagenarians and centenarians.

All of our results strongly confirmed that there was no association of cognitive impairment with levels of serum lipid/lipoprotein in community-dwelling Chinese nonagenarians and centenarians. The result of the present study showed that in community-dwelling Chinese nonagenarians and centenarians, cognitive impairment was not only independent of TC, TG, and LDL levels, but also independent of HDL levels; this was different from the two previous studies from the United States and The Netherlands $[16,17]$. It is not entirely clear whether the difference in the association of cognitive impairment with HDL in the oldest old between this study and the previous study only results from the different race.

There are many reports about abnormal levels of serum lipoprotein (including TC, TG, LDL, HDL) impairing cognitive function in the elderly [2-15]. Compared with the present study, in all these reports the participants had a significantly younger mean age and the average scores of cognitive function were significantly higher $[21,22]$. Cognitive impairment is a major component of age-related deterioration $[23,24]$. In the present study, the average score was lower than the diagnostic criteria of cognitive impairment on the MMSE and highly significant correlations (with coefficient $r=-0.129$ and -0.206 , in women and men, respectively; $\mathrm{p}<0.01$ ) existed in both genders between the score on the MMSE and age. Moreover, Imhof et al. [25] reported that in nonagenarians/ centenarians brain aging is characterized by the formation of neurofibrillary tangles and senile plaques, which 
Table 3. OR of cognitive impairment to abnormal levels of serum lipid/lipoprotein

\begin{tabular}{|c|c|c|c|c|c|c|c|c|}
\hline & \multicolumn{2}{|l|}{ TC } & \multicolumn{2}{|l|}{ TG } & \multicolumn{2}{|l|}{ LDL } & \multicolumn{2}{|l|}{ HDL } \\
\hline & $\begin{array}{l}\text { normal } \\
(<5.18)\end{array}$ & $\begin{array}{l}\text { abnormal } \\
(>5.18)\end{array}$ & $\begin{array}{l}\text { normal } \\
(<1.7)\end{array}$ & $\begin{array}{l}\text { abnormal } \\
(>1.7)\end{array}$ & $\begin{array}{l}\text { normal } \\
(<3.37)\end{array}$ & $\begin{array}{l}\text { abnormal } \\
(>3.37)\end{array}$ & $\begin{array}{l}\text { normal } \\
(>1.04)\end{array}$ & $\begin{array}{l}\text { abnormal } \\
(<1.04)\end{array}$ \\
\hline \multicolumn{9}{|l|}{ Men } \\
\hline Number of cases & 202 & 26 & 194 & 34 & 220 & 8 & 216 & 12 \\
\hline Unadjusted OR & $\begin{array}{l}1.00 \\
\text { (reference) }\end{array}$ & $\begin{array}{l}0.99 \\
{[0.43-2.28]}\end{array}$ & $\begin{array}{l}1.00 \\
\text { (reference) }\end{array}$ & $\begin{array}{l}1.16 \\
{[0.54-2.47]}\end{array}$ & $\begin{array}{l}1.00 \\
\text { (reference) }\end{array}$ & $\begin{array}{l}0.36 \\
{[0.08-1.53]}\end{array}$ & $\begin{array}{l}1.00 \\
\text { (reference) }\end{array}$ & $\begin{array}{l}1.248 \\
{[0.083-1.531]}\end{array}$ \\
\hline Multiple-adjusted $\mathrm{OR}^{1}$ & $\begin{array}{l}1.00 \\
\text { (reference) }\end{array}$ & $\begin{array}{l}1.03 \\
{[0.39-2.75]}\end{array}$ & $\begin{array}{l}1.00 \\
\text { (reference) }\end{array}$ & $\begin{array}{l}0.99 \\
{[0.43-2.29]}\end{array}$ & $\begin{array}{l}1.00 \\
\text { (reference) }\end{array}$ & $\begin{array}{l}0.24 \\
{[0.04-1.36]}\end{array}$ & $\begin{array}{l}1.00 \\
\text { (reference) }\end{array}$ & $\begin{array}{l}1.552 \\
{[0.420-5.36]}\end{array}$ \\
\hline \multicolumn{9}{|l|}{ Women } \\
\hline Number of cases & 431 & 49 & 416 & 65 & 453 & 28 & 453 & 28 \\
\hline Unadjusted OR & $\begin{array}{l}1.00 \\
\text { (reference) }\end{array}$ & $\begin{array}{l}1.45 \\
{[0.792-2.65]}\end{array}$ & $\begin{array}{l}1.00 \\
\text { (reference) }\end{array}$ & $\begin{array}{l}1.32 \\
{[0.77-2.26]}\end{array}$ & $\begin{array}{l}1.00 \\
\text { (reference) }\end{array}$ & $\begin{array}{l}1.82 \\
{[0.85-3.93]}\end{array}$ & $\begin{array}{l}1.00 \\
\text { (reference) }\end{array}$ & $\begin{array}{l}1.13 \\
{[0.51-2.52]}\end{array}$ \\
\hline Multiple-adjusted $\mathrm{OR}^{1}$ & $\begin{array}{l}1.00 \\
\text { (reference) }\end{array}$ & $\begin{array}{l}1.52 \\
{[0.793-2.90]}\end{array}$ & $\begin{array}{l}1.00 \\
\text { (reference) }\end{array}$ & $\begin{array}{l}1.12 \\
{[0.62-2.05]}\end{array}$ & $\begin{array}{l}1.00 \\
\text { (reference) }\end{array}$ & $\begin{array}{l}1.97 \\
{[0.85-4.67]}\end{array}$ & $\begin{array}{l}1.00 \\
\text { (reference) }\end{array}$ & $\begin{array}{l}1.28 \\
{[0.55-2.99]}\end{array}$ \\
\hline
\end{tabular}

Multiple logistic regression was used to estimate the OR and 95\% CI (in square brackets) of abnormal levels of serum lipid/lipoprotein as a function of increased cognitive impairment.

${ }^{1}$ Adjusted for age, BMI, smoking habits, alcohol and tea consumption, exercise, FBG, systolic blood pressure, diastolic blood pressure, sleep time during 1 day, and sleep quality.

are generally viewed as pathological change of patients with Alzheimer's disease and dementia. Thus, we can conclude that the difference in cognitive function between the old aged between 60 and 85 years and the oldest old aged 90 years or above was mainly derived from the different age. In the nonagenarian and centenarian population, the cognitive impairment due to age-related deterioration might attenuate the contribution of general risk factors for cognitive impairment, including abnormal serum levels of lipoprotein.

There were other interesting findings in the present study. Firstly, among nonagenarians and centenarians, cognitive impairment had a high prevalence; compared with men, women had a higher prevalence rate of cognitive impairment and lower scores of cognitive function. There was a difference in cognitive function between men and women among nonagenarians and centenarians. Secondly, among nonagenarians and centenarians, former and current alcohol consumption and smoking habits are related with cognitive impairment in males, but not in females. In the present study, among nonagenarians and centenarians, cognitive impairment in women was severer than in men, so cognitive impairment in women might be independent of risk factors except for age-related deterioration [26]. Moreover, men had higher prevalence rates of former and current alcohol consumption and smoking habits than women. As the prevalence rates of former and current habits in women might be too low, this might lead to an insignificant influence of these factors on cognitive impairment in women. However, we still concluded that former and current alcohol consumption and smoking habits were risk factors for cognitive impairment. This had interesting implications for the prevention of cognitive impairment in the elderly. The prevention strategies should include alcohol withdrawal and cessation of smoking from early age.

Our study had some limitations that deserve a mention. First, because of the cross-sectional nature of this study, the subjects might change their diets and the conditions related to elevated serum lipid concentrations. However, the lifestyles and food habits of the nonagenarians/centenarians were relatively stable and similar. Second, since this is a part of the PLAD, there might be a survival bias. However, this is inherent in a study of individuals of this age group. Third, we did not adjust for other potential confounding factors, such as socio-economic status and family history of cognitive impairment. Most (90\%) participants in the present study lived in the countryside, and some subjects had been working on a farm every day, and so physical activity may be a potential confounder. Thus, this population might not be representative of the urban population.

In conclusion, we found no causal association between serum lipid/lipoprotein levels and risk for cognitive impairment among Chinese nonagenarians and centenarians. If we compare the results with previous studies, this 
study indicates that among nonagenarians and centenarians, the association of cognitive impairment with abnormal levels of serum lipid/lipoprotein may change with race. Alcohol withdrawal and cessation of smoking from early age may prevent cognitive impairment among nonagenarians and centenarians.

\section{Acknowledgements}

This work was supported by the Discipline Construction Foundation of Sichuan University, and by grants from the Project of Science and Technology Bureau of Sichuan Province (2006Z09006-4), and the Construction Fund for Subjects of West China Hospital of Sichuan University (XK05001). The authors thank the staff of the Department of Geriatrics Medicine, West China Hospital and Dujiangyan Hospital, and all participants (as well as their legal proxies) for their great contribution.

\section{References}

1 Evans DA: Estimated prevalence of Alzheimer's disease in the United States. Milbank Q 1990;68:267-289.

-2 Yaffe K, Kanaya A, Lindquist K, Simonsick EM, Harris T, Shorr RI, Tylavsky FA, Newman AB: The metabolic syndrome, inflammation, and risk of cognitive decline. JAMA 2004;292:2237-2242.

-3 Moroney JT, Tang MX, Berglund L, et al: Low-density lipoprotein cholesterol and the risk of dementia with stroke. JAMA 1999; 282:254-260.

4 Evans RM, Emsley CL, Gao S, et al: Serum cholesterol, APOE genotype, and the risk of Alzheimer's disease: a population-based study of African Americans. Neurology 2000;54:240-242.

5 Notkola IL, Sulkava R, Pekkanen J, et al: Serum total cholesterol, apolipoprotein E $\varepsilon 4$ allele, and Alzheimer's disease. Neuroepidemiology 1998; 17:14-20.

-6 Romas SN, Tang MX, Berglund L, Mayeux R: APOE genotype, plasma lipids, lipoproteins, and AD in community elderly. Neurology 1999;53:517-521.

-7 Swan GE, LaRue A, Carmelli D, Reed TE, Fabsitz RR: Decline in cognitive performance in aging twins: heritability and biobehavioral predictors from the National Heart, Lung, and Blood Institute Twin Study. Arch Neurol 1992;49:476-481.

$\checkmark 8$ Reitz C, Tang MX, Manly J, Schupf N, Mayeux R, Luchsinger JA: Plasma lipid levels in the elderly are not associated with the risk of mild cognitive impairment. Dement Geriatr Cogn Disord 2008;25:232-237.

-9 Yaffe K, Barrett-Connor E, Lin F, Grady D: Serum lipoprotein levels, statin use, and cognitive function in older women. Arch Neurol 2002;59:378-384.
10 Rockwood K, Howlett S, Fisk J, Darvesh S, Tuokko H, Hogan DB, Wolfson C, McDowell I: Lipid-lowering agents and the risk of $\operatorname{cog}$ nitive impairment that does not meet criteria for dementia, in relation to apolipoprotein $\mathrm{E}$ status. Neuroepidemiology 2007;29:201207.

11 van den Kommer TN, Dik MG, Comijs HC, Fassbender K, Lütjohann D, Jonker C: Total cholesterol and oxysterols: early markers for cognitive decline in elderly? Neurobiol Aging 2007, E-pub ahead of print.

12 PanzaF, Solfrizzi V, Colacicco AM, D’Introno A, Capurso C, Palasciano R, Todarello O, Capurso S, Pellicani V, Capurso A: Cerebrovascular disease in the elderly: lipoprotein metabolism and cognitive decline. Aging Clin Exp Res 2006;18:144-148.

13 Masse I, Bordet R, Deplanque D, Al Khedr A, Richard F, Libersa C, Pasquier F: Lipid lowering agents are associated with a slower cognitive decline in Alzheimer's disease. J Neurol Neurosurg Psychiatry 2005;76:16241629.

14 Puttonen S, Elovainio M, Kivimäki M, Lehtimäki T, Keltikangas-Järvinen L: The combined effects of apolipoprotein E polymorphism and low-density lipoprotein cholesterol on cognitive performance in young adults. Neuropsychobiology 2003;48: 35-40.

15 Sarti C, Pantoni L, Pracucci G, Di Carlo A, Vanni P, Inzitari D: Lipoprotein(a) and cognitive performances in an elderly white population: cross-sectional and follow-up data. Stroke 2001;32:1678-1683.

16 Atzmon G, Gabriely I, Greiner W, Davidson D, Schechter C, Barzilai N: Plasma HDL levels highly correlate with cognitive function in exceptional longevity. J Gerontol A Biol Sci Med Sci 2002;57:M712-M715.

- 17 van Exel E, de Craen AJ, Gussekloo J, Houx P, Bootsma-van der Wiel A, Macfarlane PW, Blauw GJ, Westendorp RG: Association between high-density lipoprotein and cognitive impairment in the oldest old. Ann Neurol 2002;51:716-721.
8 Ortega RM, Requejo AM, Andrés P, LópezSobaler AM, Quintas ME et al: Dietary intake and cognitive function in a group of elderly people. Am J Clin Nutr 1997;66:803-809.

19 Tombaugh TN, McIntyre NJ: The MiniMental State Exam: a comprehensive review. J Am Geriatr Soc 1992;40:922-935.

20 Langley LK: Cognitive assessment of older adults; in Kane RL, Kane RA (eds): Assessing Older Persons. Oxford, Oxford University Press, 2000, pp 65-128.

-21 La Rue A, Koehler KM, Wayne SJ, Chiulli SJ, Haaland KY, Garry PJ: Nutritional status and cognitive functioning in a normally aging sample. Am J Clin Nutr 1997;65:20-29.

-22 Berg E, Biessels GJ, Craen AJ, Gussekloo J, Westendorp RG: The metabolic syndrome is associated with decelerated cognitive decline in the oldest old. Neurology 2007;69: 979-985.

23 Jama JW, Launer U, Witteman JCM, et al: Dietary antioxidants and cognitive function in a population-based sample of older persons. The Rotterdam Study. Am J Epidemiol 1996; 144:275-280.

24 Johnson LE: Vitamin disorders in the elderly; in Morley JE, Glick Z, Rubenstein LZ (eds): Geriatric Nutrition. New York, Raven Press, 1990, pp 117-147.

25 Imhof A, Kövari E, von Gunten A, Gold G, Rivara CB, Herrmann FR, Hof PR, Bouras C, Giannakopoulos P: Morphological substrates of cognitive decline in nonagenarians and centenarians: a new paradigm? J Neurol Sci 2007;257:72-79.

26 Corrada MM, Brookmeyer R, Berlau D, Paganini-Hill A, Kawas CH: Prevalence of dementia after age 90: results from the $90+$ study. Neurology 2008;29;71:337-343. 